\title{
Laparoscopic Repair of Paraesophageal Hiatal Hernia in a Newborn
}

\author{
Arnis Engelis */**, Klaus Schaarschmidt***, Aigars Petersons */**, Astra Zviedre**, Mohit Kakar ** \\ * Riga Stradins University, Latvia \\ ** University Children`s Hospital, Riga Latvia \\ *** Helios Clinic of Berlin-Buch, Berlin, Germany
}

\section{Summary}

A 3-month old boy was hospitalized with the suspicion of right sided pneumonia. Examination revealed hiatal or paraesophageal hernia. Ultimately, a laparoscopic operation was performed. During the operation, PEHH of the transverse colon with displaced gastro esophageal junction was discovered. Laproscopic hiatal hernia repair with modified Thal fundoplication were performed. Recovery of child 2 years after surgery was uneventful.

Key words: hiatal hernia, paraesophageal hiatal hernia type IV, laparoscopy, laparoscopic Thal fundoplication.

\section{AIM OF THE DEMONSTRATION}

The aim of this article is to demonstrate a very rare pediatric surgical pathology, paraesophageal hiatal hernia (PEHH) type IV in a 3-month old boy.

\section{CASE REPORT}

A 3-month old boy, referred by pediatrician, to University Children's Hospital, Riga was hospitalized with high fever and suspected right-sided pneumonia. His birth weight was $3670 \mathrm{~g}$, the weight at the time of hospitalization was $6165 \mathrm{~g}$, the stool was regular and there was no bloating. Later on the mother confirmed that the child "ate with difficulty" ever since his birth. The baby had been ill for 4 days with a running nose, deep cough and a high fever, up to $38.1{ }^{\circ} \mathrm{C}$, respiratory rate of 46 and hearth rate of 120 times per minute, slightly increased CRP ( $16.7 \mathrm{mg} / \mathrm{l})$ and neutrophils count $(70.3 \%)$ and had received inhalations and antibiotics. There were no pathologic respiratory sounds, merely a sharp breath. On the plain chest x-ray there was an unclear, hole-shaped shadow above the lower lobe of the right lung, which was interpreted as the abovementioned right-side pneumonia with a possible abscess formation (Fig.1). Bronchoscopy revealed thick mucus in the lower lobes of both lungs with a growth of Enterobacter Cloacae, sensitive to most antibiotics. The pictures of the following gastro-intestinal barium contrast examination were interpreted as a sliding type I hiatal hernia with the cardia and fundus of the stomach above the diaphragm. Gastric evacuation was unimpeded. Topography of the duodenum was typical. To exclude completely the congenital diaphragmatic hernia, computer tomography (CT) scan of the thorax was done. The imaging was interpreted as the cardia and fundus of the stomach and possibly the small intestinal loop located above the diaphragm, in the right side of the thorax (Fig.2). The 24-h pH-metry revealed an unanimously pathologic $11 \%$ acid reflux time below
$\mathrm{pH}$ 4. On the basis of these findings, the working diagnosis of the hiatal or paraesophageal hernia was considered and a laparoscopic hiatus repair with Thal fundoplication was planned.

The operation was performed with 4 ports of $5-\mathrm{mm}$ and an additional V-stitch for the liver retraction. Surgical exploration revealed the PEHH of the transverse colon and displaced gastro esophageal junction (PEHH type IV) (Fig.3). Puncturing of the distended colon loops and gas aspiration were performed to improve sight. The transverse colon and the stomach were carefully repositioned and a large congenital hiatal defect was revealed (Fig.4). The colonic wall did not show any signs of strangulation. After the repositioning the esophagophrenic and gastrophrenic ligaments appeared large and loose and were involved in the formation of the hernial sack. A hiatoplasty with modified Thal fundoplication were performed, and the hernia sack was partially removed. The operation lasted 3 hours 30 minutes. The postoperative course was uneventful. The child is doing perfectly well 2 years after the operation and has normal 24-hour esophageal $\mathrm{pH}$ metry results after 6 months and 2 years (we do a further control after 5 years routinely).

\section{DISCUSSION}

Statistically, hiatal hernia type I or the sliding hiatal hernia of the stomach has been estimated to form the largest incidence rate with $95 \%$ or more of all hiatal hernias in children, while types II, III and IV accounts for the rest of $5 \%$ of all paraesophageal hiatal hernias (PEHH). In contrast to sliding hiatal hernia, PEHH is a true hernia which usually contains the stomach or a part of it along with the small intestine, spleen, colon, or combinations of these organs $(4,10)$. Transverse colon is the rarest content of PEHH and in children only very few cases have been reported so far, therefore differential diagnosis with congenital diaphragmatic 
hernia can be difficult. The displaced transverse colon is usually symptomatic but not strangulated $(3,4,6,9)$. PEHH generally requires surgical treatment $(1,4,8,12)$. $\mathrm{PEHH}$ is very rare in adults comprising less than $5 \%$ of all hiatal hernias together $(5,11)$. In children it is an extremely rare condition and the exact incidence is not reported $(2,7,10,13)$. Symptoms of PEHH vary considerably; from asymptomatic cases or cases with scarce, non-specific clinical picture to severe, sometimes even life-threatening conditions (5). Similar is the case with type IV PEHH in a infant which is exceedingly rare and has been mentioned in only a few publications $(2,4,7,10,13)$. The symptoms and clinical course in our patient are similar to those reported in the literature. A suspected unclear pneumonia on the $x$-ray picture is a typical reason directing such patients to a pediatric surgeon. Transverse colon as content of PEHH has a rather protracted clinical course with chronic respiratory infection and disorders of defecation rather than acute complications as reported by others $(4,7,10)$.

Surgical treatment in the case of PEHH is the single solution and should not be postponed unnecessarily. In case of severe symptoms an emergency operation is necessary. In most cases the conventional Nissen fundoplication has been suggested as an antireflux procedure, and during the open procedure the hernia sack has been fully or partially removed $(1,8)$. Laproscopic operation in the case of PEHH has been mentioned in the literature, however it has been described as much more challenging compared with the laparoscopic antireflux procedure in gastro-esophageal reflux disease. We found one report of 2 cases, where open Thal fundoplication was performed in the $\mathrm{PEHH}$ type III (12). No reports have been found, where the laparoscopic Thal fundoplication would have been done in the PEHH type VI. In our case the reposition of the transverse colon, the stomach and esophagus was technically easy, therefore the partial excision of the hernia sack and the antireflux procedure took up most of the operation time. In our opinion, the modified laparoscopic Thal fundoplication in this case was very satisfactory from a technical point of view and so far successful in the long run. Therefore we use it as a standard procedure in all cases of gastroesophageal reflux, hiatus hernia and PEHH in infants.

\section{Conflict of interest: None}

\section{REFERENCES}

1. Al-Sahem AH. Congenital paraesophageal hernia in infancy and childhood // Saudi Med J, 2000; 21:164-7

2. Chandrasekar S, Welch RJ, Watson H. Congenital mixed hiatus hernia in a neonate // Arc Dis Child Fetal Neonatal Ed, 2006; 91:F317

3. Hong JY, Song KY, Kim KW, Lee WK, Ha JG, Choi SO. Two cases of congenital paraesophageal hiatal hernia in infancy // J Korean Pediatr Soc, 2000; 43:1613 - 20

4. Imamoglu M, Cay A, Kosucu P, Ozdemir O, Cobanoglu U, Orhan F, Akyol A, Sarihan H. Congenital paraesophageal hiatal hernia: pitfalls in the diagnosis and treatment// J Pediatr Surg, 2005; 40:1128 - 33

5. Kahrilas PJ, Pandolfino JE. Hiatus hernia // GI Motility Online, 2006; doi:10.1038/gimo48.http:// www.nature.com/gimo/contents/ptl/full/gimo48. html.

6. Karpelowsky JS, Wieselthaler N, Rode H. Primary paraesophageal hernia in children // J Pediatr Surg, 2006; 41:1588 - 93

7. Koulopoulos K, Kostelestos S, ChristopoulosGeroulanos G, Mauridis G, Kalantzi N, Condilis N, Plataras C, Skanavis K, Kerammidas D. Paraesophageal hernia in childhood// Ann Ital Chir, 2006; 77:57 - 8

8. Kundal AK, Zargar NU, Krishna A. Laparoscopic repair of paraesophageal hiatus hernia in infancy // J Indian Assoc Pediatr Surg, 2008; 13:142 - 143

9. Ozkan H, Nergul Y. A massive hiatal hernia that mimics a congenital diaphragmatic hernia. An unusual presentation of hiatal hernia in childhood. Case Report // Surgery Today, 2002; 32:1072 - 4

10. Samujh R, Kumar D, Rao KLN. Paraesophageal hernia in the neonatal period: suspicion on chest X-ray// Indian Pediatr, 2004; 41:189 - 91

11. Vandenplas Y, Hassal E. Mechanisms of gastro esophageal reflux and gastro esophageal reflux disease // J Pediatr Gastroenterol Nutr, 2002; 35:119- 36

12. Van der Zee DC, Bax NM, Kramer WL, Mokhaberi B, Ure BM. Laparoscopic management of a paraesophageal hernia with intrathoracic stomach in infants// Eur J Pediatr Surg, 2001; 1 1:52 - 4

13. Yazici M, Karaca I, Etensel B, Temir G, Gunsar C, Guclu C, Mutaf O. Paraesophageal hiatal hernias in children // Dis Esophagus, 2003; 16:210 - 3

\author{
Address: \\ Arnis Engelis \\ Department of Pediatric Surgery \\ University Children's Hospital \\ Vienibas gatve 45, Riga, LV-1004, Latvia \\ E-mail: arengelis@yahoo.com
}




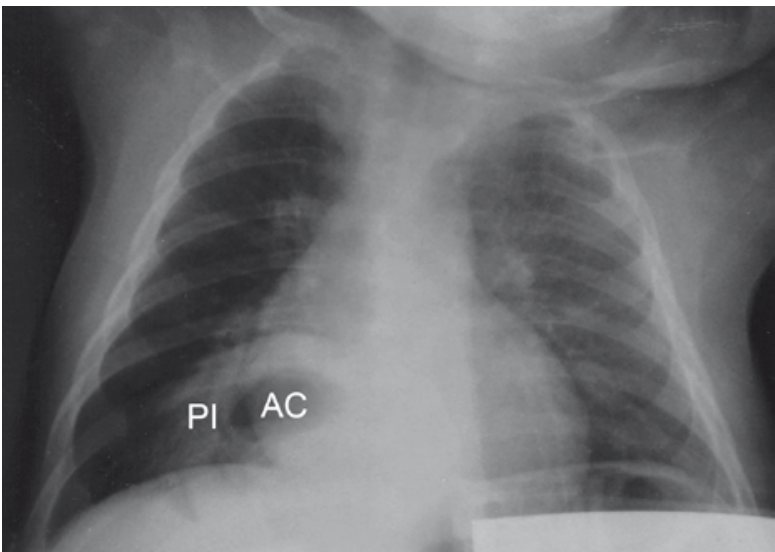

Fig. 1. Inicial thorax X-ray image. PI - suspected right side pneumonia infiltration; $A C$ - suspected abscess cavity

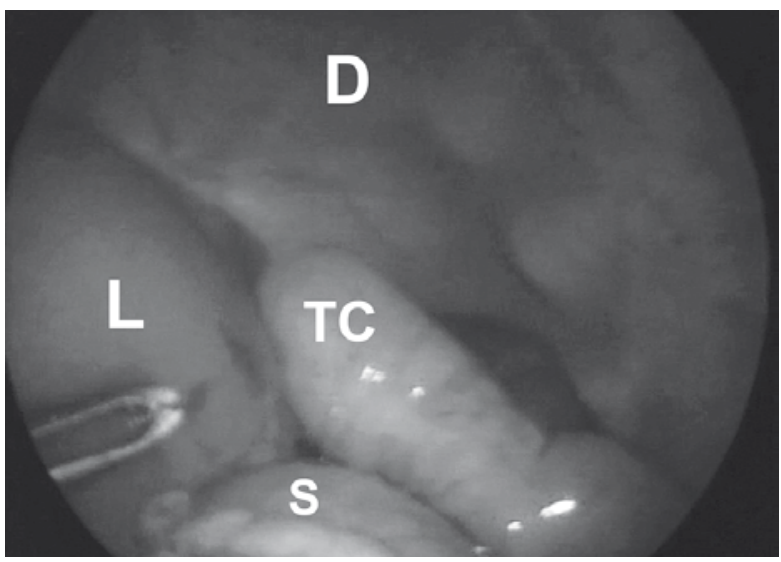

Fig. 3. Laparoscopic view. TC - transverse colon loop retreating through hiatus esophagi at the beginning of the procedure. L - liver; D diaphragm; $S$ - stomach

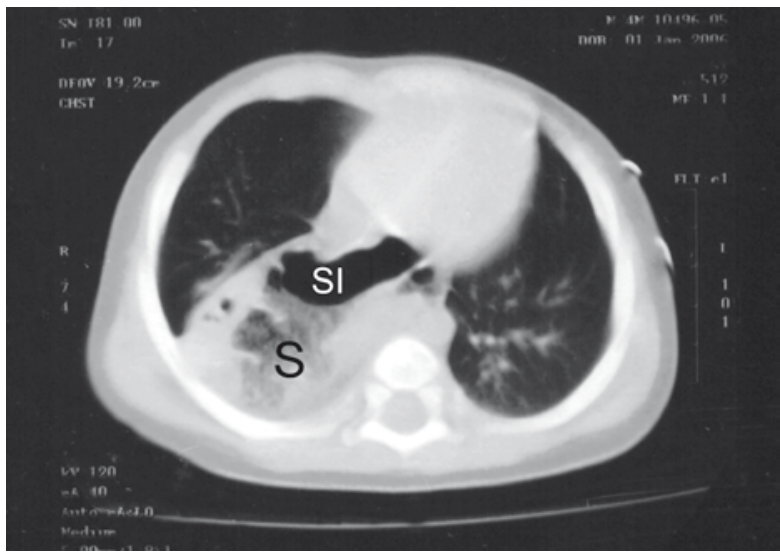

Fig. 2. Thorax computed tomography scan. S stomach; SI - was interpreted as the small intestine in the right posterior part of the thorax

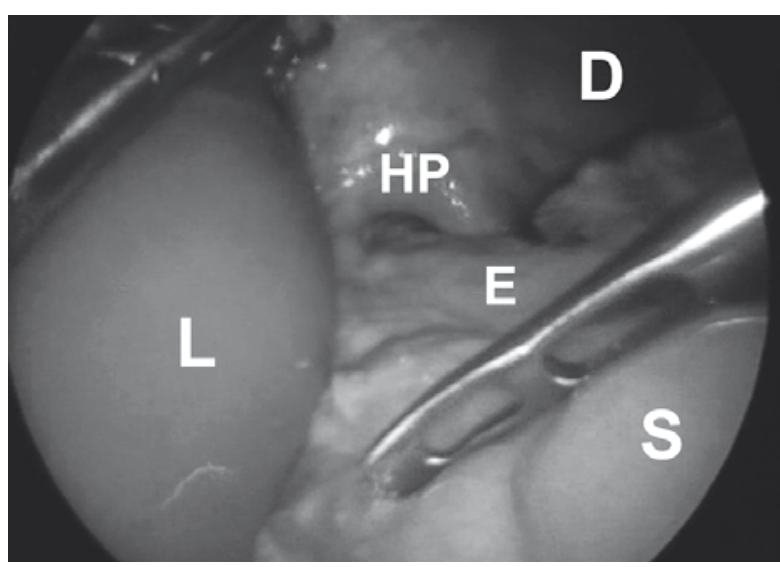

Fig. 4. Laparoscopic view. HP - paraesophageal hiatal hernia port; E - esophagus; S - stomach; L liver; D - diaphragm 